\title{
Quality Control of Lead-Acid Battery according to Its Condition Test for UPS Supplier and Manufacturers
}

\author{
Tsung-Chih Hsiao, ${ }^{1}$ Tzer-Long Chen, ${ }^{2}$ Chia-Hui Liu, ${ }^{3}$ Chih-Ming Lee, \\ Hsin-Chun Yu, ${ }^{5}$ and Tzer-Shyong Chen ${ }^{5}$ \\ ${ }^{1}$ College of Computer Science and Technology, Huaqiao University, Xiamen, Fujian 361021, China \\ ${ }^{2}$ Department of Technological Product Design, Ling Tung University, Taichung 40852, Taiwan \\ ${ }^{3}$ Department of Digital Literature and Arts, St. John's University, Taipei 25135, Taiwan \\ ${ }^{4}$ Tunghai University, Taichung 40704, Taiwan \\ ${ }^{5}$ Department of Information Management, Tunghai University, Taichung 40704, Taiwan
}

Correspondence should be addressed to Tzer-Shyong Chen; arden@thu.edu.tw

Received 11 June 2014; Accepted 17 July 2014; Published 25 September 2014

Academic Editor: Teen-Hang Meen

Copyright (C) 2014 Tsung-Chih Hsiao et al. This is an open access article distributed under the Creative Commons Attribution License, which permits unrestricted use, distribution, and reproduction in any medium, provided the original work is properly cited.

The risk of insufficient petroleum resources has forced human beings to emphasize the acquisition and storage of energy. To avoid such situation, this study tends to explore the effective management of lead-acid batteries for effective utilization conforming to the industrial requirements.

\section{Introduction}

The advance of information technology has enhanced people's requirements for the quality of life. Nevertheless, the risk of insufficient petroleum resources has forced human beings to emphasize the acquisition and storage of energy. In 2006, two types of batteries appeared in the US top ten technology plan, in which lead-acid batteries covered one-third of the gross sales in the battery industry. In addition to the close relations with power, traffic, and information, lead-acid batteries presented the control power in the transportation, like vehicles and various uninterruptible power systems so as to become a necessary product in human life. Lead-acid batteries [1] would become the new green energy system with the best development and application in the 21st century.

The boom of green industry makes resource reengineering and energy conservation the key issues for enterprises to invest in a lot of resources to protect the environment. For instance, green economy or green industry has been regarded as the key development in China's 12th Five-Year Plan. Apparently, green industry is not only an emerging industry but also a trend. Particularly, the global focus on energy protection in the past years has promoted the concepts of energy conservation and carbon reduction. Besides, the shortage of oil production, natural gas, and coal makes the resource application extraordinarily important. A lot of researchers therefore constantly study energy conservation, aiming to effectively utilize the present resources on the earth for the extreme benefits. This study aims to achieve the energy conservation and environmental protection through the effective management of lead-acid batteries.

According to the reports in Mainland China, lead-acid battery producers are requested to recycle the products, meeting the requirements of the industrial management in Mainland China for it is the embodiment of social responsibility as well as the key in the sustainable development of green economy. For enterprises, secondary lead, as the cold iron in reducing costs and enhancing efficiency, has played a critical role in the increasing production of lead-acid batteries [2]. Meanwhile, the pollution risk is increasing in the secondary lead processing that the nation is promoting the recycling industry. The environmental capacity of lead-acid battery recycle system is practiced in the nation based on provinces, and the threshold for the industries is enhanced. Apparently, 
the officials in Mainland China have constantly planned and invested in green economy and presented regulations for the production of lead-acid batteries in order to protect the citizens' health and the economic development from being damaged by lead-acid battery pollution.

The lead-acid battery industry is the key in the development of secondary energy that battery enterprises have stressed on the applications to consumer products. Lead-acid batteries, which are mainly applied to the energy storage of vehicles, uninterruptible power supply (UPS), electric cars, medical equipment, and communication devices, have been used for a century land provided that the market structure is mature and stable. In order to maintain the normal operation of precision instruments in high-tech plants and medical industry, uninterruptible power supply is often utilized for keeping the power supply stable. Nevertheless, uninterruptible power supply requires a large amount of lead-acid batteries [3], which could lead to heavy metal pollution and endanger the citizens' health if it lacks proper management. Moreover, plug-in electric vehicles, as one of the seven strategic emerging industries, are considered promising but still encounter problems in costs, markets, and security, showing the extraordinary importance of lead-acid battery management in the environmental pollution. To avoid such a situation, this study tends to explore the effective management of lead-acid batteries for effective utilization conforming to the industrial requirements.

Lead-acid batteries are widely applied and play a primary role in human demands, such as the equipment of information, telecommunication, traffic, industry, and medical systems. Lead-acid batteries are mainly applied to high-tech plants and medical industry, particularly to uninterruptible power supply, which has to be discarded every few years as it is used as a spare. The chemical pollution of lead and sulfuric acid in the process of dealing with used batteries could seriously impact the environment. Hence, the effective management of lead-acid batteries is considered as a critical issue $[4,5]$. Nonetheless, it is currently not easy to test the residual capacity and the service life of lead-acid batteries, which are affected by the battery structure, environmental temperature, depth of previous discharge, self-discharge of batteries, discharge current, charge method, and end of discharge voltage $[6,7]$. Besides, the capacity change during the leadacid battery discharge is not linear, and some aged batteries would appear decreased in voltage. In the real situation, not all batteries could be measured offline, and the charge voltage measured online could result in misjudging the battery voltage. Besides, not all aged batteries would present decreased voltage. In this case, battery voltage could not entirely be used for judging battery ageing. It is regarded as a dilemma to test lead-acid batteries [8]. As a result, a lot of battery-capacity detecting technologies are proposed in the market, including open circuit voltage, electrolyte specific gravity, load voltage, internal resistance, charge ripple current monitoring, and offline load control, for various conditions [9-12]. In consideration of time, accuracy, and online detection, this study aims to discuss the state of availability, residual capacity, and service life of lead-acid batteries with the introduction of scene management.
The dynamic characteristics of lead-acid batteries are complicated and would change with battery ageing. However, the research on the management of lead-acid battery testing tends to explore the effectiveness of lead-acid batteries for the users to understand the power supply, the capacity, and the discard time to ensure the system stability and the maximal effectiveness. The maintenance cost could be reduced by verifying the health of each battery and providing managerial strategies to ensure the discard time of batteries, and the maintenance strategy is adjusted from advancing the currently time-based regular discard to condition-based according to the real discharge testing. Instantaneous current discharge, a highly reliable online testing with low destruction, is introduced and can actually record DC resistance, float voltage, discharge voltage, and recovery voltage in the discharge process for analyzing the single battery capacity and capability. Moreover, it allows online testing and the reliability of uninterruptible power supply in plants to be maintained. Such an approach is expected to accurately estimate the state of availability to find out the degraded batteries for early discard and ensure the system reliability. This study aims to

(1) find out degraded batteries for early discard and ensure the reliability of uninterruptible power supply,

(2) verify the health of each battery to ensure the actual discard time and reduce the maintenance costs,

(3) test online without affecting the normal operation of systems.

This paper is expected to achieve the objectives of predictive maintenance and effective utilization of batteries, energy conservation, cost reduction, and environmental protection. The managerial experiences and approaches of lead-acid battery suppliers and technology plants are considered as the reference of this study. By analyzing and recording the data, the research results are inferred from the effective data, which could be the reference of enterprises and the academia. The enterprises therefore could decrease the waste of leadacid battery discard and reduce the discard cost. What is more, the heavy metal pollution caused by lead-acid battery discard could be reduced through the effective management of lead-acid batteries so as to protect the environments and contribute to the earth.

\section{Related Work}

2.1. State and Characteristics of Lead-Acid Batteries. The battery state could be divided into state of charge and state of health, in which several correlations and parameters that could affect the battery performance $[4,13]$ are contained. The relations between the states are shown in Figure 1.

Lead-acid batteries present the characteristics of battery capacity and voltage, discharge characteristics, and preservation of lead-acid batteries [14], which are further introduced as follows.

(1) Battery Capacity and Voltage. For a battery with fixed capacity, the relations between the discharge current and the discharge time are not linear, and the discard time would 


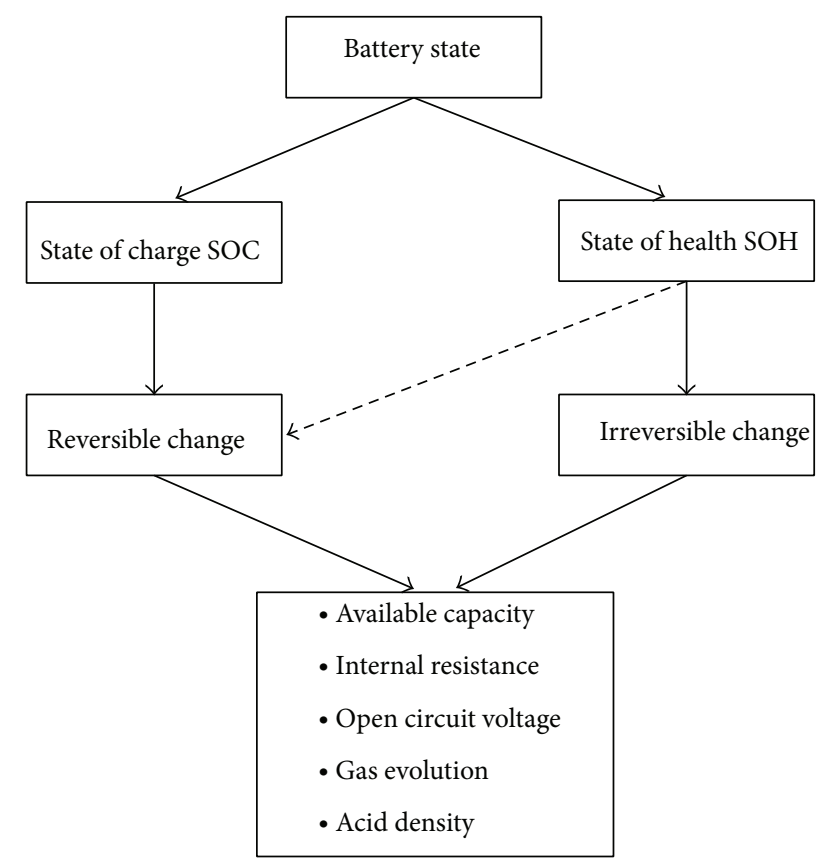

FIgURE 1: Battery state flow.

change with changing discharge current. When discharging a battery with rated current, the provided capacity conforms to the rated capacity. However, the battery capacity would obviously decrease when the battery is discharged with the current larger than the rated current. For this reason, the setting of end of discharge voltage (EODV) normally would change with changing discharge current. Battery capacity would be affected by the end voltage, discharge current, and environmental temperature. The rated capacity of close leadacid batteries is set by a $20 \mathrm{~h}$ discharge rate $(20 \mathrm{HR})$. The battery capacity is also influenced by the environmental temperature that the environmental temperature about $0-40^{\circ} \mathrm{C}$ is the optimal range for discharge. When the environmental temperature is higher than $40^{\circ} \mathrm{C}$, the battery performance would degrade. The potential difference between the negative and the positive poles is regarded as the battery voltage. The voltage of a single lead-acid battery is about $2 \mathrm{~V}$. The concentration of sulfuric acid could present the changes of battery capacity. In this case, measuring the open circuit voltage could acquire the battery capacity [15-18].

(2) Discharge Characteristics. During discharge, lead-acid batteries show the characteristics of larger capacity being supplied by the discharge with low current and smaller capacity being supplied by high-current discharge. Such factors could cause difficulties in judging the residual capacity and service life of a battery. The discharge current reveals correlations with the end voltage of a battery that the lower end voltage appears on the higher discharge current. Since the chemical reaction in the end of battery discharge causes bad conductivity in a battery, the internal resistance increases and the voltage rapidly decreases so that the end voltage of valve regulated lead-acid batteries would change with the discharge rate. Low end voltage would be set for high-current discharge, while high end voltage is set for low-current discharge. Since the product would be decreased when discharging with high current, the polar plate would not be damaged with low discharge voltage. Nonetheless, low-current discharge for a long time could result in product obstruction on the negative polar plate to deform the polar plate, cause short circuit, and directly affect the service life that the end voltage is generally higher. Consequently, the discharge voltage for valve regulated lead-acid batteries could not be lower than the estimated end of discharge voltage; otherwise, the batteries might fail and can no longer be charged when being overdischarged $[17,19]$.

(3) Preservation of Lead-Acid Batteries. The optimal storage conditions for lead-acid batteries container are $-15 \sim 30^{\circ} \mathrm{C}$, and the relative humidity is $25 \sim 85 \%$, not being directly exposed in sun and dust-free places. Lead-acid batteries present internal self-discharge reaction, that is, the reaction between lead and sulfuric acid generating sulfuric acid lead and hydrogen. Such a reaction would be accelerated with increasing temperature to decrease the capacity and reduce the voltage. For this reason, batteries kept for more than 3 months should be recharged before the delivery. In the process of packaging, transit, and storage, the battery capacity would be slightly reduced due to the self-discharge and temperature. The capacity of lead-acid batteries therefore would gradually decrease with time. When the self-discharge exceeds the normal range, the open circuit voltage would decrease that too much sulfuric matter on the polar plate would permanently reduce the battery capacity and advance the failure. As a result, batteries should be stored in cool and dry places as the higher temperature a battery is kept in the higher discharge rate.

\subsection{Service Life of Lead-Acid Batteries and the Check Standard.} Regarding the irreversible life of lead-acid batteries, a battery is considered terminated when the dischargeable capacity is lower than $80 \%$ of rated capacity, according to IEEE Std 1188. In accordance with the discharge capability, the service life of lead-acid batteries could be divided into

(1) stable phase, with more than $100 \%$ discharge capability,

(2) decline phase, with $100 \% \sim 80 \%$ discharge capability,

(3) breakdown phase, with $80 \% \sim 35 \%$ discharge capability.

When the discharge capability is lower than $80 \%$, the internal polar plate would rapidly degrade and enter breakdown phase, when the battery should be discarded, according to IEEE Std 1188. Nevertheless, a battery can still serve for a long period of time after the time point. In consideration of the operation costs, lowering the discharge capability standard for battery discard could reduce the cost and increase the profit. However, the internal polar plate enters breakdown phase with rapid degradation that the quality of power supply for equipment might be affected and even cause operation risks and loss when the discard time is delayed. Therefore, 
it is a major issue for battery managers making the optimal discard time.

The judgment of battery life is generally defined according to the usage, including cycle life and float life.

(1) Cycle Life. It refers to the number of times a battery is being charged and discharged, which is used as the key power with frequent charge/discharge, being repeatedly charged and discharged when the capacity decreases down to a certain value $(60 \%$ or $80 \%)$ of the initial value. Depth of discharge (DOD) is the major factor in cycle life of lead-acid batteries that the higher depth of discharge would reduce the number of times of cycle life [13].

(2) Float Life. Float life indicates treating the batteries as the standby power, such as uninterruptible power supply (UPS), when the battery life is calculated by time. For instance, lead-acid batteries in uninterruptible power supply in technology plants are used as a spare, with the float state, and merely discharged when the normal power is exceptionally interrupted. Charge current is the major factor in float life that continuous charge current could result in the erosion of electrode plates [20]. Temperature, which could accelerate the erosion of electrode plates, is regarded as another factor in float life that being in a high-temperature environment could rapidly damage the batteries. Since the charge way and temperature could affect the service life of batteries, the factors in shortening the battery life are concluded [21].

(a) Depth of discharge: overdischarge could shorten cycle life.

(b) Large-current discharge: discharge with small capacity and then large current could shorten the service life.

(c) Large-current charge: the gas generated by extreme charge current could exceed the absorption rate of batteries at a certain amount to increase the internal pressure causing the gas being exhausted from the security valve. The electrolyte therefore would be largely consumed to damage the components in the battery.

(d) Overcharge: the components in a battery would be damaged by the electrolyte resulting from overcharge.

(e) Effects of environmental temperature: high temperature would accelerate the degradation of components in a battery. The battery life would be shortened when charging with fixed voltage but unnecessary large current in high temperature. Hydrogen generated in extreme low-temperature charge could increase the internal pressure or decrease the electrolyte to shorten the service life.

2.3. State Detection of Lead-Acid Batteries. Current technologies for measuring the lead-acid battery state contain open circuit voltage, electrolyte specific gravity, internal resistance, charge ripple current monitoring, and offline load control
[22]. They are introduced in this section, and the measurement used for this experiment is selected [23].

(1) Open Circuit Voltage. The residual capacity and the open circuit voltage of a battery appear in linear relationship that the open circuit voltage could be used for judging the battery state. However, after charging/discharging lead-acid batteries, the open circuit voltage required time, about $30 \mathrm{~min}-1 \mathrm{hr}$, for recovery and being stable. When the battery state is predicted with the open circuit voltage in this period, it would reveal certain errors. The measurement of float voltage could check seriously damaged open circuit and short circuit batteries but could not judge the discharge capability of each battery. For measuring the open circuit voltage, it required $2 \mathrm{hrs}$ offline for balancing the electrolytic reaction so as to judge the state of charge. Moreover, batteries should be kept in the float state in uninterruptible power supply that open circuit voltage is rather unsuitable $[24,25]$.

(2) Electrolyte Specific Gravity. The electrolyte is the mixture of pure sulfuric acid and distilled water under the temperature $80^{\circ} \mathrm{F}$ and the standard specific gravity 1.280 . Hydrometer method is used for measuring the specific gravity change of the electrolyte in a battery, as the concentration of acid liquor in the electrolyte would decrease when discharging lead-acid batteries and is proportional to the battery state. A hydrometer therefore is utilized for measuring the specific gravity of the electrolyte as well as predicting the residual capacity of the battery [19]. Nonetheless, each battery has to be measured its electrolytic concentration which would consume more time and increase manpower costs. Besides, the electrolyte is limited that the spread speed and the specific gravity appear lower in the upper layer but higher in the lower layer during charging/discharging that stratification is generated to affect the estimation of the battery state.

(3) Internal Resistance. For internal resistance, the resistance change, during the battery discharge, is used for estimating the residual capacity of a battery [18]. At the end of the battery discharge, the internal resistance would rapidly increase that the rapidly increasing resistance could be regarded as the end of the battery capacity. However, such an approach is restricted to the precision of resistance measurement, and the resistance have certain relations with the service life that a battery being used for a long period of time would appear in higher internal resistance, resulting in causing prediction errors. Internal resistance is likely affected by online charge current and ripples so that the reproducibility of the read value is bad (the rate of change about 20 25\%). Internal resistance could orientate the exceptional resistance, which is one of the key judgments in battery failure [26-29].

(4) Charge Ripple Current Monitoring. When ageing and passivation appear in a series of batteries, the capacitive reactance change would affect the ripple current in the charge current. Such an approach could establish a long-term ageing judgment of a series of batteries but could not diagnose a single battery. Besides, the ripple current could have errors because of the capacitor failure of rectifier, charger, load 
change, and DC Bus that other testing methods should be taken into account.

(5) Offline Load Control. To test the left capacity of a battery, off-line load control, is suitable for the acceptance of uninterruptible power supply. However, the setting of the end voltage should be emphasized in deep discharge to prevent the battery from being damaged.

(6) Instantaneous Current Discharge. The batteries provide the power through electrochemical reaction. The chemical voltage measured in a short period of time could be an online test with high reliability and low destruction. The external load is utilized for instantaneous current discharge when DC resistance, float voltage, discharge voltage, and recovery voltage are recorded. It allows measuring batteries without stopping the devices and easily controlling the single battery capacity and capability.

In accordance with the experimental requirements in this study, instantaneous current discharge is chosen for measuring lead-acid batteries for it could easily control the current state of batteries and exclude unnecessary resistance errors. Hence, the testing data are more precise for analyzing the state and the discharge capability of lead-acid batteries. In order to achieve the effective management of lead-acid batteries, the successive management is further evaluated according to the analyzed data.

\section{Measurement and Practice of ACID Batteries}

3.1. Research Variables. Based on the research variables of batteries, current, voltage, and battery state, the unit and codes are defined as follows:

(1) Battery Code (NO.).

(2) Service Time (Time; Unit: Month).

(3) Float Voltage (FV; Unit: V).

(4) Discharge Voltage (DV; Unit: V).

(5) Discharge Current (DA; Unit: A).

(6) Internal Resistance ( $R$; Unit: $\mathrm{m} \Omega$ ).

(7) Battery State (Check; 1: OK, 2: WARNING, 3: EXCEPTION).

3.2. Research Hypotheses. The following hypotheses are proposed for the batteries so as to exclude some special situations and make the research results more precise.

(1) The longer service time (Time), the lower discharge voltage (DV).

(2) The longer service time (Time), the higher internal resistance $(R)$.

(3) Battery state (Check) is correlated with service time (Time), discharge voltage (DV), and internal resistance $(R)$.
3.3. Research Design. To effectively test the state and discharge capability of lead-acid batteries in uninterruptible power supply in technology plants, instantaneous current discharge is selected as the measurement in this study by testing the battery state with a measuring device and analyzing the tested discharge data with software.

According to the process, more than two people are required to securely and accurately complete the research. The measuring devices are checked in the beginning of the research to ensure the usability. The condition of uninterruptible power supply is further confirmed to exclude the exception. The operation and evacuation routes are also confirmed for the operators' security. Furthermore, the measuring device parameters are set for starting the experiment. In the testing process, each cell checked the discharge characteristics every $0.5 \mathrm{sec}$, and the characteristics of recovery voltage are also measured every $0.5 \mathrm{sec}$ for testing the terminal voltage change. In addition, the voltage monitoring terminal is connected to the terminal of energy storage pool and the discharge current probe is directly linked to the battery terminal for diagnoses. The device is also checked for the misconnection. When there is exception resulting from misconnection, the device would alert the operator to ensure the operation security. Finally, the measured data are read for data analyses to explore the effective information for the effective management of the personnel in technology plants and cost reduction.

3.4. Research Methodology. Instantaneous current discharge is selected as the measurement in this study, as it is suitable for measuring the state of lead-acid batteries in uninterruptible power supply in technology plants with the following advantages.

(1) Instantaneous current discharge could control the capacity state and the starting ability of a single battery.

(2) DC resistance measured from the real discharge could be used for analyzing the degradation of polar plates and the terminal break and false welding of power collector as well as avoiding AC resistance errors.

(3) The float voltage data are applied to understanding the balance analysis of charge voltage and the examination of short circuit batteries.

(4) The recovery voltage data allow analyzing the factors in the electrolytic degradation.

An instantaneous discharge device is utilized in this study for finding out the degraded batteries with the testing information and preceding the control according to the current time and state of lead-acid batteries to assist technology plants in achieving the effective management.

In accordance with instantaneous current discharge, the relationship between lead-acid battery voltage and time is applied to collecting the testing data for the statistical analyses of service time, internal resistance, discharge voltage, and float voltage, which are compared with basic statistical analysis, regression analysis, and discriminated analysis for the effective management. 
3.5. Research Devices and Practice. Based on the above research process, this study practiced measuring device checking, uninterruptible power supply checking, researcher security, measuring equipment parameter setting, float voltage testing, and discharge testing for effectively testing the battery state and understanding the real change time of batteries to reduce the costs.

(1) Measuring Device Checking. The state and maintenance of the measuring devices should be checked before the measurement so as to accurately test the state of lead-acid batteries in uninterruptible power supply and reduce errors. Five minutes are expected to check the measuring devices and the accessories, including the measuring devices of operational power, voltage measuring tool, discharge probe, data transmission line, $13 \mathrm{~mm}$ spanner, and analysis software, the other tools of multimeter, standby battery, and discharge probe levelling tools of sandpaper, wirecutter, and needlenose plier. The specific check proceeds after completing the checking and preparations.

(2) Uninterruptible Power Supply Checking. Uninterruptible power supply in technology plants is regarded as the research subject in this study. Proceeding with uninterruptible power supply checking to confirm the state of uninterruptible power supply could prevent the experimental errors and protect the security of the personnel. Five minutes are estimated for the confirmation of uninterruptible power supply, including uninterruptible power supply operating state, lead-acid battery appearance, environmental condition, charge setting, and operating space, and the other tools and machinery of multimeter, uninterruptible power supply panel, thermometer, and visual inspection and hands. The specific confirmation proceeds after the checking and preparations.

(3) Researcher Security. There are risks in instantaneous current discharge that complete preparations are required for ensuring the researchers' security. It takes about three minutes for the researchers to put on the protective garments, including Insulating Gloves, Long-Sleeves Work Suit, and Insulating Tool. Measuring operation manual is followed for the operation and wearing so as to ensure the researchers being in the optimal security. The specific confirmation proceeds after the checking and preparations.

(4) Measuring Device Parameter Setting. The measuring device parameters are set after the preparations in order to precisely measure the experimental data. The devices are functioned DATE, USER CODE, BATT GROUP, BATT NO., DATE OF MFG, and CURRENT. The parameters are set and operated according to measuring body device, battery specification, and measuring operation manual.

(5) Float Voltage Testing. Float voltage testing is done before the discharge testing. Connecting the voltage probe for float voltage measurement, the conducting strip of the battery is checked to ensure the tight lock. The testing system is further checked to avoid invalid data caused by errors. The devices cover measuring body device, measuring tool-voltage probe, battery specification, and measuring operation manual.

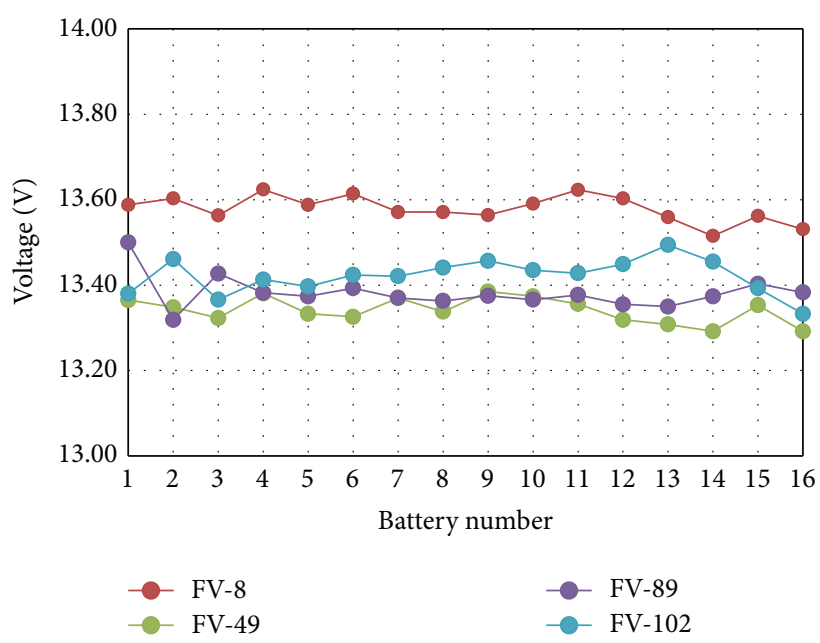

FIGURE 2: Float charge voltage of the lead-acid batteries.

(6) Discharge Testing. A discharge probe needs to be equipped in the initial discharge testing. The discharge testing of a single lead-acid battery can be completed within $1 \mathrm{sec}$ (including discharge for $0.5 \mathrm{sec}$ ). The data are further confirmed to avoid invalidity. The devices include measuring body device, measuring operation manual, discharge work-current probe, and measuring tool-voltage clamp.

\section{Measuring Results and Analysis}

4.1. Collection and Organization of Variable Data. The batteries in uninterruptible power supply in technology plants are discussed in this study. Total 16 batteries are recorded in the actual measurement, and total 64 pieces of data are acquired by recording Battery code (NO.), service time (Time; Unit: month), float voltage (FV; Unit: V), discharge voltage (DV; Unit: V), discharge current (DA; Unit: A), internal resistance ( $R$; Unit: $\mathrm{m} \Omega$ ), battery state (Check; 1: OK, 2: WARNING, 3: EXCEPTION) at the time points at 8, 49, 89, and 102 months. For judging battery state (Check), a battery is first judged as exceptional when the discharge current is less than $80 \%(80 \mathrm{~A})$ of the set $100 \mathrm{~A}$. Second, an unfavorable discharge voltage condition is considered when discharge voltage DV $<90 \%(12.15 \mathrm{~V})$ of the rated $13.5 \mathrm{~V}$. Third, when the resistance is 1.75 times $(7 \mathrm{~m} \Omega)$ larger than the initial $4 \mathrm{~m} \Omega$, the internal resistance is unfavorable. Each unfavorable condition is added 1 to the battery state. Moreover, float voltage (FV) is affected by the charge voltage during online measurements that the measured value is merely regarded as the reference but not considered for the judgment. According to the statistical data diagram of lead-acid batteries at 8,49 , 89 , and 102 months (Figure 2), float voltage of the lead-acid batteries at the 8th month is higher than the values of other aged lead-acid batteries, while float voltage at other months is not significantly related to battery time, possibly because of the effects of series-connected charge voltage.

The experimental results show that discharge voltage of lead-acid batteries tends to be stable with the value in 12.712.2. However, comparing the batteries which are placed for 


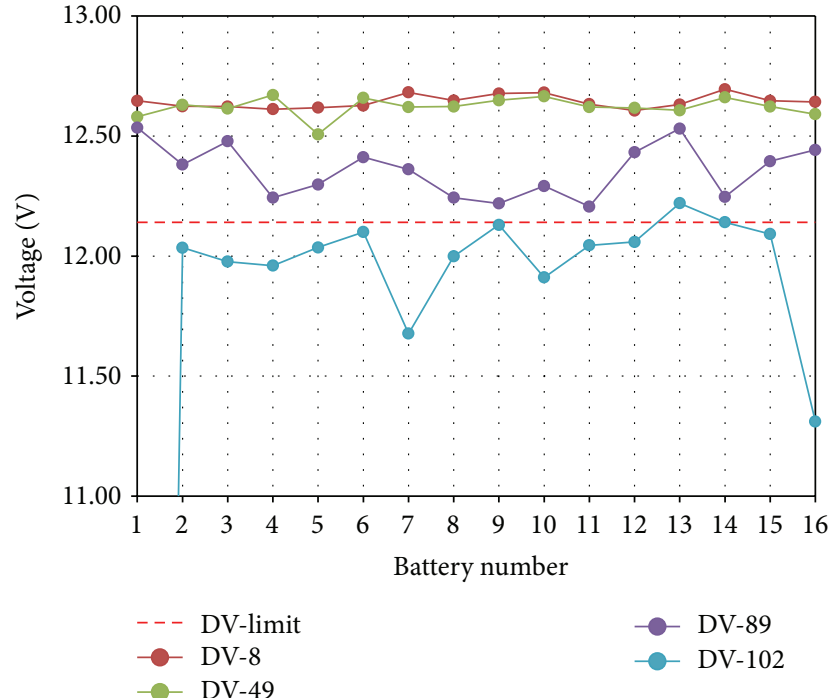

FIGURE 3: Discharge voltage of lead-acid batteries.

102 months with the control lead-acid batteries, discharge voltage gradually decreases. From the line graph of discharge voltage (Figure 3), the voltage of lead-acid batteries, which are placed for 102 months, obviously weakens, presenting the positive proportion of the degradation and time.

In accordance with the statistical data of batteries at 8, 49, 89 , and 102 months, the internal resistance at the 8 th month is smaller, while the relative large value is revealed at the 102nd month when problems are likely to appear. From Figure 4, batteries with longer service time would start degrading internally, resulting in increasing internal resistance.

By observing the testing data, 16 batteries in 8 months are OK, showing the low probability of EXCEPTION; 15 batteries in 89 months are OK; merely one presents WARNING, showing that the batteries start degrading but are still secure. The battery state change therefore should be concerned for the management. Three batteries in 102 months show WARNING, and the rest 12 batteries reveal EXCEPTION, presenting the serious battery degradation that batteries after 102 months can no longer be used. In this case, the managers should make decisions on the battery discard.

4.2. Statistical Analyses. Table 1 shows the statistics of mean, median, maximum, minimum, and standard deviation.

The regression analysis of the samples involve service time (Time) and discharge voltage (DV); according to the analysis, the model correlation coefficient is low as shown as Table 2, and the data are checked for excluding the outlier.

After excluding the outlier, the test on service time (Time) and discharge voltage (DV) keeps do regression analysis; according to it, the model correlation coefficient increases up to 0.6072 . Apparently, discharge voltage of lead-acid batteries would be affected by service time that the negative correlation appears under the significance 5\%. It shows that the longer service time would reduce discharge voltage (Table 3 ).

The regression analysis on service time (Time) and internal resistance $(R)$ goes on, by which the model correlation

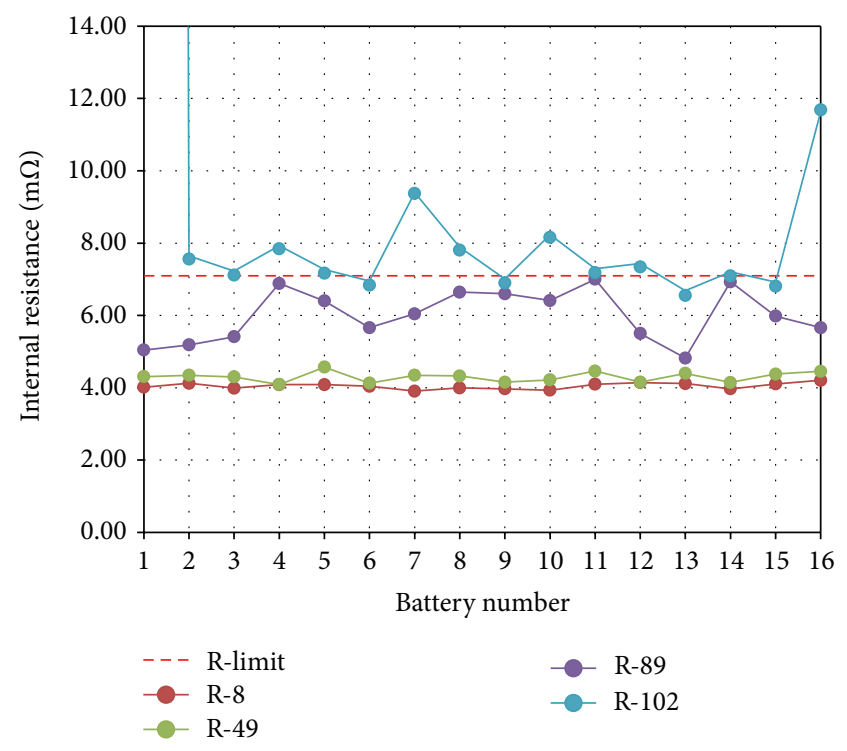

FIgURE 4: Internal resistance of lead-acid batteries.

coefficient reveals 0.6538 , presenting the effects of service time on lead-acid battery resistance. The positive correlations appear under the significance $1 \%$ that the longer service time could enhance internal resistance (Table 4).

Regression analysis is preceded for battery state (Check) towards internal resistance $(R)$ and discharge voltage (DV). The model correlation coefficient shows 0.7507 , revealing the negative correlation between lead-acid battery state and discharge voltage under the significance $1 \%$. It presents that the lower discharge voltage would worsen the battery condition. The remarkable correlation between internal resistance and battery state is not as good as discharge voltage, showing that both discharge current (DA) and discharge voltage should be measured for judging the battery condition (Table 5).

Finally, the measurement of discriminant analysis has to be done. The normal (OK) samples present $75 \%$, the ones with WARNING show $6.25 \%$, and the defective ones (NG) reveal $18.75 \%$, where misjudging $\mathrm{OK}$ as $\mathrm{NG}$ appears once, $2.08 \%$. In summary, the normal judgment (OK) appears to be $97.92 \%$, the ones of WARNING present $100 \%$, and the defective ones (NG) are $100 \%$. The overall misjudgment proportion presents the accuracy of the verification. Table 6 shows the data in check discriminant analysis.

4.3. Management Structure. The experimental results of leadacid batteries show the positive proportion between the battery degradation and time. The change appears on the end of battery life when it accelerates the degradation. Figure 5 shows the discharge voltage/internal resistance distribution of the 64 batteries. Similar to the previous analyses, the longer service time would decrease discharge voltage and enhance internal resistance.

It is suggested in IEEE Std 1188 that lead-acid batteries with the discharge capability lower than $80 \%$ should be discarded. Nevertheless, batteries can still be used for a period of time after the time point (as the measured discharge 
TABLE 1: Basic statistics.

\begin{tabular}{lcccccc}
\hline Variable & Time & FV & DV & DA & $R$ & 12.605 \\
Mean & 62 & 13.431 & 12.224 & 98.656 & 100 & 4.697 \\
Median & 69 & 13.393 & 12.533 & 12.695 & 100 & 461.551 \\
Maximum & 102 & 13.624 & 13.292 & 0.666 & 14 & 3.906 \\
Minimum & 8 & 0.097 & 1.496 & 10.750 & 57.032 \\
Standard deviation & 37.081 & & & 1 & 0.794 \\
\hline
\end{tabular}

TABLE 2: Service time and discharge voltage of regression analysis.

\begin{tabular}{lcccccc}
\hline Variable & Coefficient estimates & Standard deviation & $t$-value & $P$ value & Significant & $R$-square \\
\hline Constant & 12.937 & 0.354 & 36.54 & $<0.0001$ & $1 \%$ & 0.0665 \\
Time & -0.0115 & 0.0049 & -2.34 & 0.0224 & $5 \%$ & \\
\hline
\end{tabular}

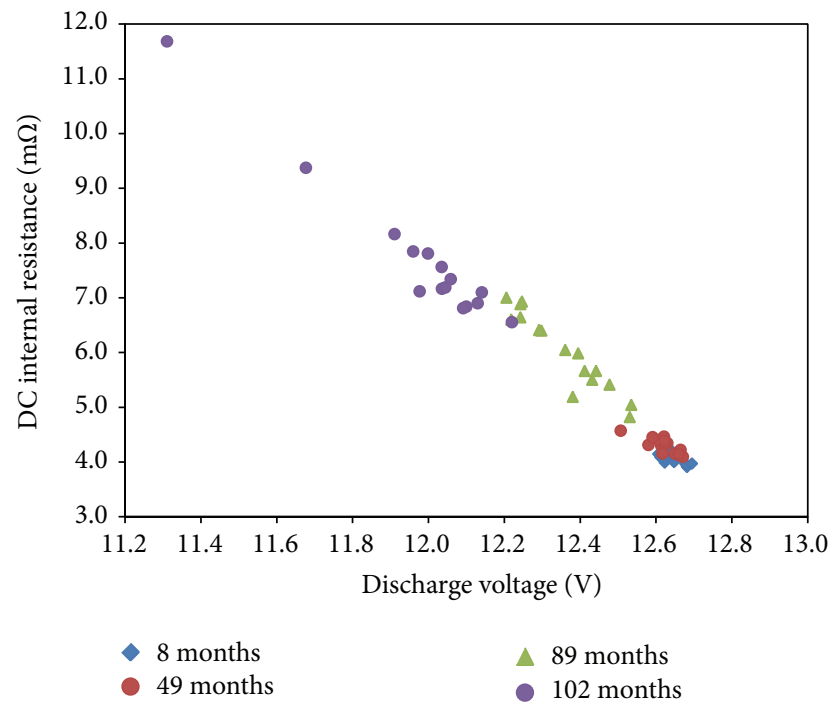

FIGURE 5: Discharge voltage/internal resistance distribution.

voltage in Figure 5 merely shows 1 sample not being able to be discharged, while the rest of the samples could meet the requirement of the rated discharge current). In consideration of the operation cost, lowering the limit for discard could reduce the cost. However, the late changing time might affect the stable device operation and influence the operation of the plant to cause loss.

Based on the internal standard process, the lead-acid batteries in uninterruptible power supply should be discarded after 4 years (48 months). When the data showed WARNING, service time might be prolonged to 7 years. In the case company, total 9,559 lead-acid batteries were purchased in different years. According to the standard process, about 136.8 million NT dollars are required for battery discard in 2004-2020. When the discard time is prolonged to 7 years (84 months), total 88.215 million NT dollars is required for battery discard in 2004-2020. Total 48.595 million NT dollars therefore could be reduced in the 16 years that about 3 million NT dollars is reduced annually.
The analysis results show that the approach could accurately judge the battery state. Except bad quality or end of battery life, internal resistance and discharge voltage degrade slowly and continuously, which might be measured after several months. Based on the concept, the battery maintenance is classified into new, midterm, and end-term for tests. New batteries are the ones newly purchased, which could be defined as feedstock tests when the batteries are tested in the beginning of purchase so as to reduce the risk of bad quality. Moreover, there are several factors in the residual capacity and service life of lead-acid batteries, including battery structure, environmental temperature, depth of previous discharge, self-discharge, discharge current, charge method, and end of discharge voltage. The end-term batteries are therefore defined as service time over a half of the battery life. The test is then shortened from 6 months to 3 months, expecting to find out the breakdown, proceeding with maintenance and discard, and ensure the system reliability, other than those defined as midterm batteries, which are relatively stable and show lower risks of breakdown. The test proceeds once a year to reduce the work load of the testing personnel.

\section{Conclusion}

Aiming at the management of degrading lead-acid batteries in uninterruptible power supply in technology plants, a testing method not affecting the online testing is selected. A battery testing process is established according to the research results, expecting to change the time-based regular testing into active condition-based maintenance, which detects the device parameters and adopts proper maintenance before the exception or breakdown. Such a testing strategy presents the following features.

(1) In consideration of time, accuracy, and online detectability, the discharge is checked in short time, and DC resistance, float voltage, discharge voltage, and charge voltage are recorded in the process to provide a testing method for battery state.

(2) The battery management is provided for technology plants, expecting to verify the health of each battery, find out the degraded batteries for discard, and 
TABLE 3: Regression analysis (excluding outliers).

\begin{tabular}{lcccccc}
\hline Variable & Coefficient estimates & Standard deviation & $t$-value & $P$ value & Significant & $R$-square \\
\hline Constant & 12.787 & 0.0450 & 283.93 & $<0.0001$ & $1 \%$ & 0.6072 \\
Time & -0.0062 & 0.0006 & -9.84 & $<0.0001$ & $5 \%$ & \\
\hline
\end{tabular}

TABLE 4: Service time and internal resistance of regression analysis.

\begin{tabular}{lcccccc}
\hline Variable & Coefficient estimates & Standard deviation & $t$-value & $P$ value & Significant & $R$-square \\
\hline Constant & 3.2847 & 0.2354 & 13.96 & $<0.0001$ & $1 \%$ & 0.6538 \\
Time & 0.0358 & 0.0033 & 10.87 & $<0.0001$ & $1 \%$ & \\
\hline
\end{tabular}

TABLE 5: Battery state, internal resistance, and discharge voltage.

\begin{tabular}{lcccccc}
\hline Variable & Coefficient estimates & Standard deviation & $t$-value & $P$ value & Significant & $R$-square \\
\hline Constant & 86.9502 & 14.9149 & 5.83 & $<0.0001$ & $1 \%$ & $1 \%$ \\
DV & -6.5462 & 1.1146 & -5.87 & $<0.0001$ & 0.7507 \\
$R$ & -0.7881 & 0.2002 & -3.94 & 0.0002 & $1 \%$ & \\
\hline
\end{tabular}

TABLE 6: Battery state of discriminant analysis.

\begin{tabular}{lcccc}
\hline Check & OK & Warning & NG & Total \\
\hline \multirow{2}{*}{ OK } & 47 & 0 & 1 & 48 \\
& $97.92 \%$ & $0 \%$ & $2.080 \%$ & $100 \%$ \\
\hline \multirow{2}{*}{ Warning } & 0 & 4 & 0 & 4 \\
& $0 \%$ & $100 \%$ & $0 \%$ & $100 \%$ \\
\hline \multirow{2}{*}{ NG } & 0 & 0 & 12 & 12 \\
& $0 \%$ & $0 \%$ & $100 \%$ & $100 \%$ \\
\hline
\end{tabular}

confirm the actual discard time of batteries. Hence, it is able to ensure the system reliability and provide users with managerial strategies.

(3) Aiming at reducing the maintenance cost, current time-based regular testing for advance discard is adjusted to condition-based maintenance based on the discharge tests.

Under the fierce competition in modern technology industry, cost reduction is always the requirement of managers. Nevertheless, in consideration of device operation maintenance and system stability, the optimal device maintenance strategy could minimize the maintenance cost and maximize the system stability.

In the regular testing process, setting the measuring cycle might be difficult. A long cycle might reduce the number of testing times but increase the risk of exceptional batteries not being checked. A short cycle could cause overmaintenance and manpower load because of the increasing number of testing times and testing manpower costs. Factors in battery life are numerous that instantaneous current discharge is applied to establishing a management method in this study. It could not only ensure the system stability in the plant but also acquire the maximal use effectiveness, reduce the maintenance cost, enhance the company competitiveness, and reduce the impact of used batteries on the environment by decreasing unnecessary battery discard so as to contribute to the environmental protection and waste reduction.

\section{Conflict of Interests}

The authors declare that there is no conflict of interests regarding the publication of this paper.

\section{Acknowledgment}

This work was supported partially by the introduction of talents Huaqiao University Scientific Research Projects (Project no. 13BS412).

\section{References}

[1] I. Papič, "Simulation model for discharging a lead-acid battery energy storage system for load leveling," IEEE Transactions on Energy Conversion, vol. 21, no. 2, pp. 608-615, 2006.

[2] J. N. Harb, V. H. Johnson, and D. Rausen, "Use of a fundamentally based lead-acid battery model in hybrid vehicle simulations," in Proceedings of the Annual Electrochemical Society Conference, Washington, DC, USA, 1999.

[3] J. M. McAndrews and R. H. Jones, "A valve regulated lead acid battery management system (VMS)," in Proceedings of the 18th International Telecommunications Energy Conference (INTELEC '96), pp. 507-513, Boston, Mass, USA, October 1996.

[4] H. Oman, "Making Batteries Last Longer," IEEE Aerospace and Electronic Systems Magazine, vol. 14, no. 9, pp. 19-21, 1999.

[5] H. Oman, "Battery developments that will make electric vehicles practical," IEEE Aerospace and Electronic Systems Magazine, vol. 15, no. 8, pp. 11-21, 2000.

[6] P. M. Hunter and A. H. Anbuky, "VRLA battery virtual reference electrode: battery float charge analysis," IEEE Transactions on Energy Conversion, vol. 23, no. 3, pp. 879-886, 2008.

[7] P. E. Pascoe and A. H. Anbuky, "VRLA battery discharge reserve time estimation," IEEE Transactions on Power Electronics, vol. 19, no. 6, pp. 1515-1522, 2004. 
[8] S. T. Hung, D. C. Hopkins, and C. R. Mosling, "Extension of battery life via charge equalization control," IEEE Transactions on Industrial Electronics, vol. 40, no. 1, pp. 96-104, 1993.

[9] Z. M. Salameh, M. A. Casacca, and W. A. Lynch, "A mathematical model for lead-acid batteries," IEEE Transactions on Energy Conversion, vol. 7, no. 1, pp. 93-98, 1992.

[10] M. Kozaki and T. Yamazaki, "Remaining battery capacity meter and method for computing remaining capacity," US Patent, vol. 5, no. 691, p. 78, 1997.

[11] C. C. Chan, E. W. C. Lo, and S. Weixiang, "The available capacity computation model based on artificial neural network for leadacid batteries in electric vehicles," Journal of Power Sources, vol. 87, no. 1-2, pp. 201-204, 2000.

[12] H. Mori, K. Itou, H. Uematsu, and S. Tsuzuki, "An artificial neural-net based method for predicting power system voltage harmonics," IEEE Transactions on Power Delivery, vol. 7, no. 1, pp. 402-409, 1992.

[13] C.-C. Hua and M.-Y. Lin, "A study of charging control of leadacid battery for electric vehicles," in Proceedings of the IEEE International Symposium on Industrial Electronics (ISIE '00), pp. 135-140, Cholula, Mexico, December 2000.

[14] J. D. Farmer and J. J. Sidorowich, "Predicting chaotic time series," Physical Review Letters, vol. 59, no. 8, pp. 845-848, 1987.

[15] T. Yamazaki, K. Sakurai, and K. Muramoto, "Estimation of the residual capacity of sealed lead-acid batteries by neural network," in Proceedings of the 20th International Telecommunications Energy Conference (INTELEC '98), pp. 210-214, San Francisco, Calif, USA, October 1998.

[16] E. M. Valeriote, T. G. Chang, and D. M. Jochim, "Fast charging of lead-acid batteries," in Proceedings of the 9th Annual Battery Conference on Applications and Advances, pp. 33-38, Long Beach, Calif, USA, January 1994.

[17] C. S. C. Bose and F. C. Laman, "Battery state of health estimation through coup de fouet," in Proceedings of the 22nd International Telecommunications Energy Conference, pp. 597-601, 2002.

[18] M. J. Hlavac and D. Feder, "VRLA battery monitoring using conductance technology," in Proceedings of the the 17th International Telecommunications Energy Conference (INTELE '95), pp. 284-291, 2005.

[19] J. H. Aylor, A. Thieme, and B. W. Johnson, "A battery state-ofcharge indicator for electric wheelchairs," IEEE Transactions on Industrial Electronics, vol. 39, no. 5, pp. 398-409, 1992.

[20] J. P. Cun, J. N. Fiorina, M. Fraise, and H. Mabboux, "The experience of UPS company in advance battery monitoring," in Proceedings of the INTELEC, pp. 22-25, 1996.

[21] S. S. Misra and L. S. Holden, "UPS battery life characteristics," in Proceedings of the 6th IEEE Battery Conference on Applications and Advances, pp. 11-19, 1991.

[22] C. T. Lin and P. F. Hsu, "Forecast of non-alcoholic beverage sales in Taiwan using the grey theory," Asia Pacific Journal of Marketing and Logistics, vol. 14, no. 4, pp. 3-12, 2002.

[23] R. Z. Toll and M. R. Moore, "Real-time capacity prediction and uncertainty for vrla products: a customer's [end use] perspective," in Proceedings of the 24th Annual International Telecommunications Energy Conference, pp. 115-120, 1992.

[24] C. Y. Kung, M. T. Ho, and L. C. Chen, "The application of GM(1, 1) model of grey prediction to supply and demand of doctor manpower for otolaryn geologists in Taiwan," in Proceedings of the 3rd IASTED International Conference Advances in Computer Science and Technology, pp. 544-548, 2009.
[25] H. Morita, T. Kase, Y. Tamura, and S. Iwamoto, "Interval prediction of annual maximum demand using grey dynamic model," International Journal of Electrical Power and Energy Systems, vol. 18, no. 7, pp. 409-412, 1996.

[26] J. D. Kozlowski, "A novel online measurement technique for AC impedance of batteries and other electrochemical systems," in Proceedings of the 16th Annual Battery Conference on Applications and Advances, pp. 257-262, Long Beach, Calif, USA, January 2001.

[27] J. M. Hawkins and R. G. Hand, "AC impedance spectra of fieldaged VRLA batteries," in Proceedings of the 18th International Telecommunications Energy Conference (INTELEC '96), pp. 640-645, Boston, Mass, USA, October 1996.

[28] G. J. Markle, "AC impedance testing for valve regulated cells," in Proceedings of the IEEE 14th International Telecommunications Energy Conference, pp. 212-217, October 1992.

[29] J. Garche and A. Jossen, "Battery management systems (BMS) for increasing battery life time," in Proceedings of the 3rd International Telecommunications Energy Special Conference (TELESCON '00), pp. 81-88, Dresden, Germany, 2000. 


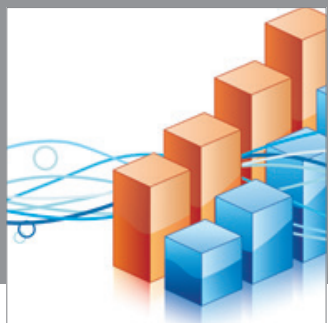

Advances in

Operations Research

mansans

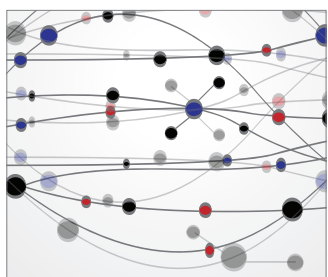

The Scientific World Journal
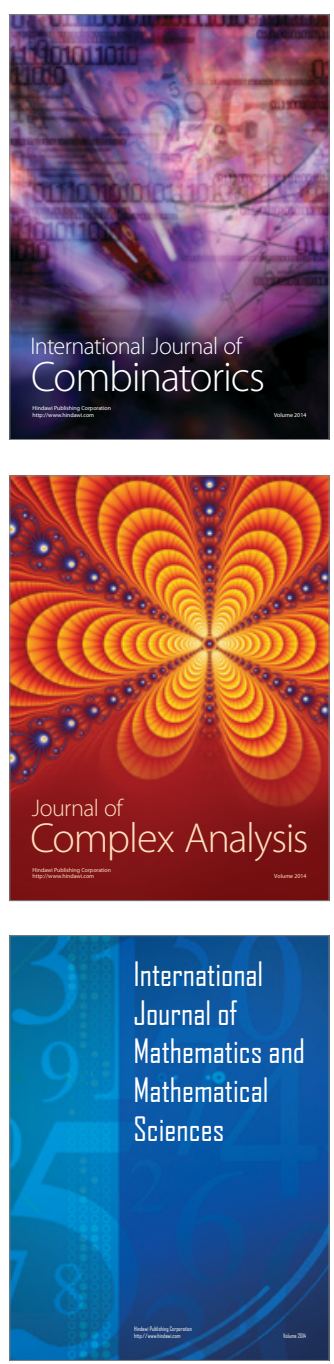
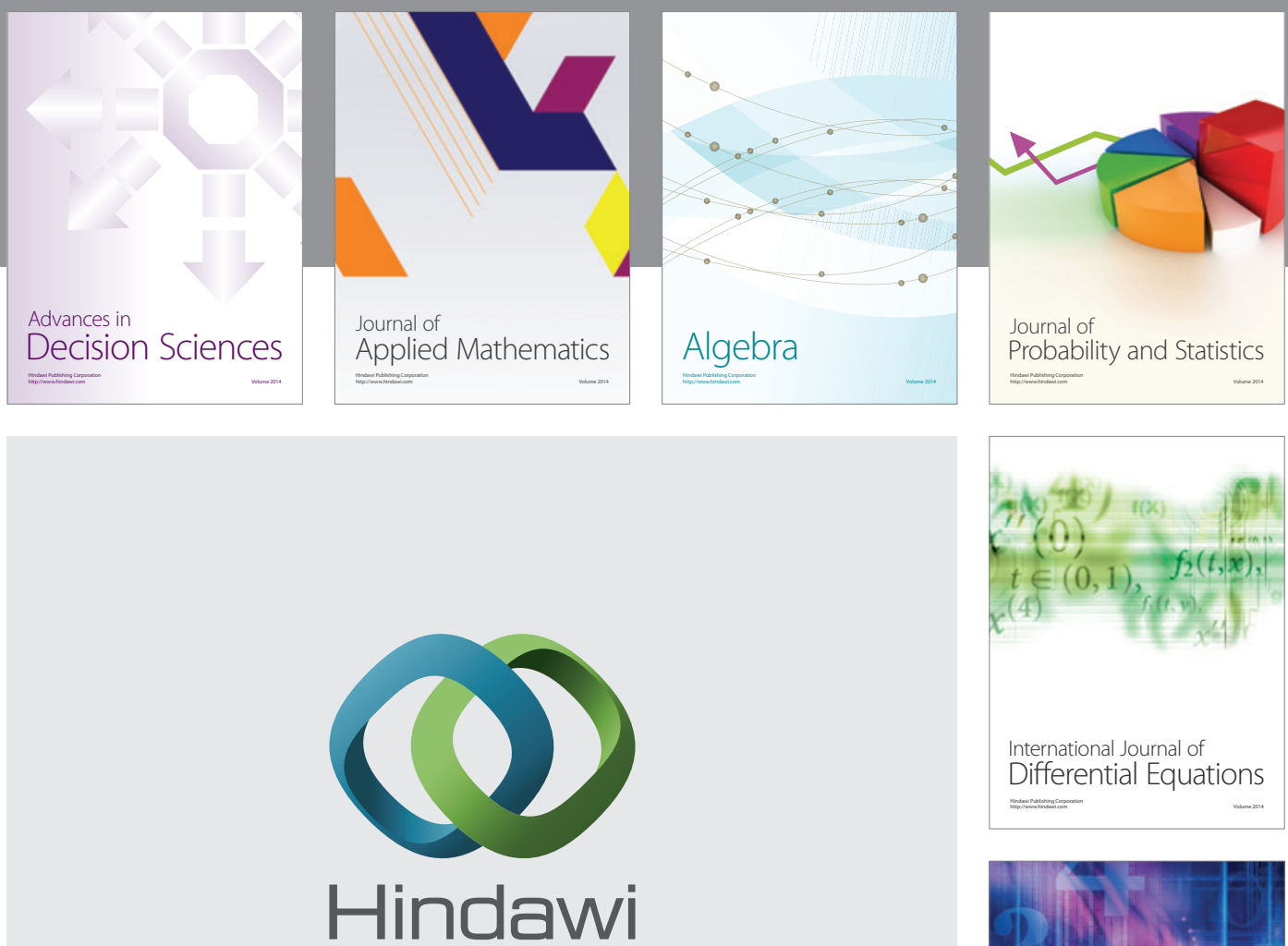

Submit your manuscripts at http://www.hindawi.com
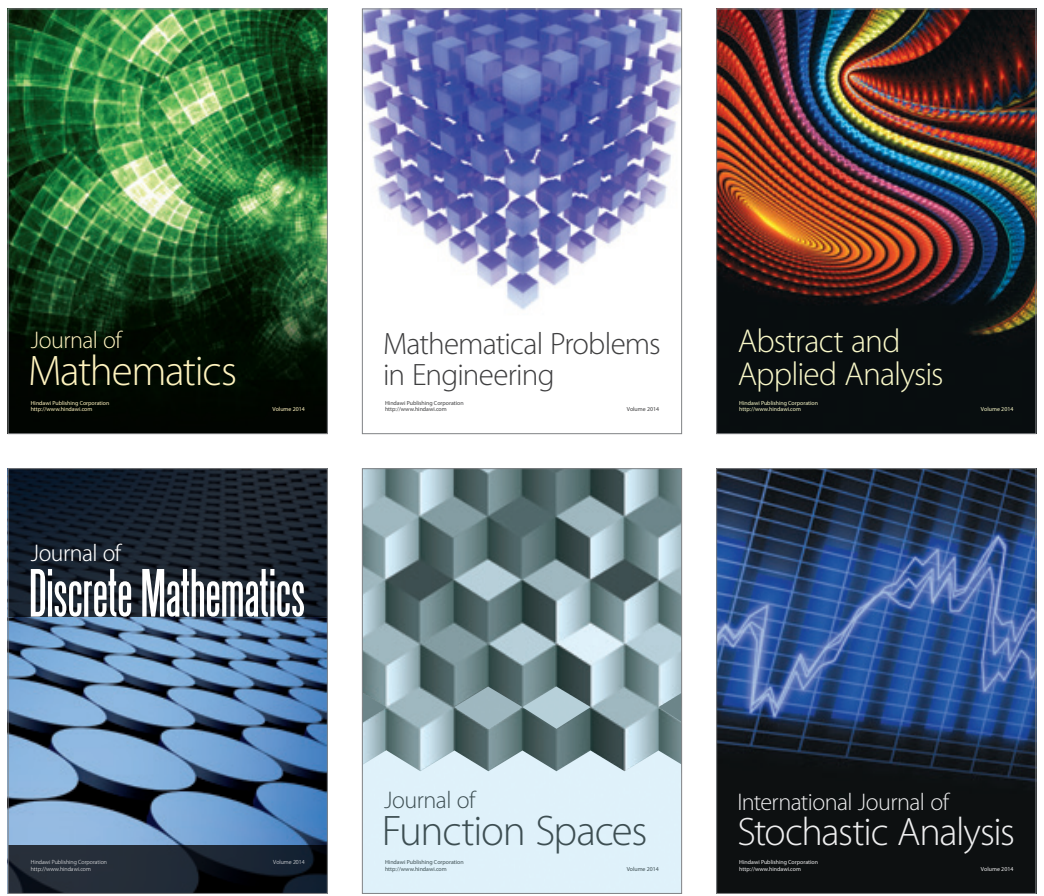

Journal of

Function Spaces

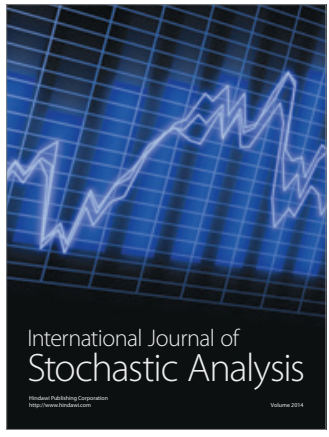

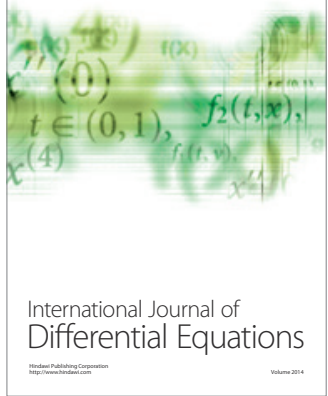
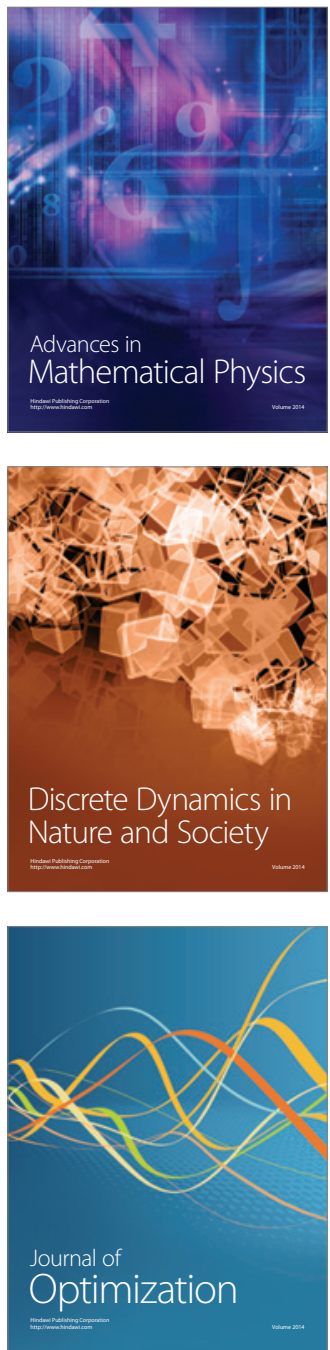